\title{
Phytotoxicity of $\mathrm{ZnO}$ nanoparticles and the released $\mathrm{Zn}$ (II) ion to corn (Zea mays L.) and cucumber (Cucumis sativus $\mathbf{L}$.) during germination
}

\author{
Ruichang Zhang ${ }^{1,3} \cdot$ Haibo Zhang ${ }^{2}$ C Chen $\mathrm{Tu}^{2} \cdot$ Xuefeng $\mathrm{Hu}^{2} \cdot$ Lianzhen $\mathrm{Li}^{2}$ • \\ Yongming Luo ${ }^{1,2} \cdot$ Peter Christie $^{4}$
}

Received: 24 October 2014 / Accepted: 5 March 2015 / Published online: 22 March 2015

(C) Springer-Verlag Berlin Heidelberg 2015

\begin{abstract}
Toxicity of engineered nanoparticles on organisms is of concern worldwide due to their extensive use and unique properties. The impacts of $\mathrm{ZnO}$ nanoparticles ( $\mathrm{ZnO} N P s)$ on seed germination and root elongation of corn (Zea mays L.) and cucumber (Cucumis sativus L.) were investigated in this study. The role of seed coats of corn in the mitigation toxicity of nanoparticles was also evaluated. ZnO NPs $\left(1,000 \mathrm{mg} \mathrm{L}^{-1}\right)$ reduced root length of corn and cucumber by $17 \%(p<0.05)$ and $51 \%(p<0.05)$, respectively, but exhibited no effects on germination. In comparison with $\mathrm{Zn}^{2+}$, toxicity of $\mathrm{ZnO} \mathrm{NPs}$ on the root elongation of corn could be attributed to the nanoparticulate $\mathrm{ZnO}$, while released $\mathrm{Zn}$ ion from $\mathrm{ZnO}$ could solely contribute to the inhibition of root elongation of cucumber. $\mathrm{Zn}$ uptake in corn exposed to $\mathrm{ZnO}$ NPs during germination was much higher than that in corn exposed to $\mathrm{Zn}^{2+}$, whereas $\mathrm{Zn}$ uptake in cucumber was significantly correlated with soluble $\mathrm{Zn}$ in suspension. It could be inferred that $\mathrm{Zn}$ was
\end{abstract}

Responsible editor: Philippe Garrigues

Electronic supplementary material The online version of this article (doi:10.1007/s11356-015-4325-x) contains supplementary material, which is available to authorized users.

Yongming Luo

ymluo@yic.ac.cn

1 Key Laboratory of Soil Environment and Pollution Remediation, Institute of Soil Science, Chinese Academy of Sciences, Nanjing 210008, China

2 Key Laboratory of Coastal Environmental Processes and Ecological Remediation, Yantai Institute of Coastal Zone Research, Chinese Academy of Sciences, Yantai 264003, China

3 University of Chinese Academy of Sciences, Beijing, China

4 Agri-Food and Biosciences Institute, Newforge Lane, Belfast BT9 5PX, UK taken up by corn and cucumber mainly in the form of $\mathrm{ZnO}$ NPs and soluble Zn, respectively. Transmission electron microscope confirmed the uptake of ZnO NPs into root of corn. Although isolation of the seed coats might not be the principal factor that achieved avoidance from toxicity on germination, seed coats of corn were found to mitigate the toxicity of $\mathrm{ZnO}$ NPs on root elongation and prevent approximately half of the $\mathrm{Zn}$ from entering into root and endosperm.

Keywords $\mathrm{ZnO}$ nanoparticles $\cdot$ Phytotoxicity $\cdot$ Root elongation · Germination · Corn · Cucumber · Seed coats . Uptake

\section{Introduction}

A variety of engineered nanoparticles (ENPs) are being developed and incorporated into commercial products due to their unique physicochemical properties comparing with bulk materials. It is estimated that the annual value of nanotechnologyrelated products is expected to reach $\$ 3$ trillion by 2020 (Roco et al. 2011). Such widespread and expanding production and application of nanoparticles increase their potential release into the environment, raising concerns within the scientific and regulatory communities about their potential environmental impacts (Colvin 2003).

Metal oxide nanoparticles such as $\mathrm{ZnO}$ nanoparticles $(\mathrm{ZnO}$ NPs) are of particular interest due to their extensive use in varied commercial products from sunscreens and cosmetics to abrasives in slurries used for semiconductor manufacturing (Ju-Nam and Lead 2008) and subsequently are increasingly discharged into the environment. Although the environmental concentrations of most ENPs remain unknown, exposure modeling suggests that ENPs concentrations in soil are higher than those in water and air, implying that soil may be a major 
sink for ENPs released into the environment (Ge et al. 2011; Gottschalk et al. 2009). The predicted concentration in soil of $\mathrm{ZnO}$ NPs that are being used or could be used in cosmetics and personal care products and coatings has reached a few milligrams per kilogram (Boxall et al. 2007). Furthermore, it has been estimated that the environmental concentrations of $\mathrm{ZnO}$ NPs in sludge treated soil may increase at rates as great as 1.6 to $3.3 \mu \mathrm{g} \mathrm{kg}^{-1}$ year $^{-1}$ (Gottschalk et al. 2009). However, $\mathrm{ZnO}$ NPs released into soil potentially have profound impacts on terrestrial ecosystems. They were found to be toxic to bacteria (Adams et al. 2006; Brayner et al. 2006; Heinlaan et al. 2008) and the earthworm (Hu et al. 2010), and they alter the composition of the soil bacterial community by reducing both microbial biomass and diversity (Ge et al. 2011). Dissolution of $\mathrm{ZnO}$ NPs has been extensively demonstrated (Bian et al. 2011). Few studies reported that phytotoxicity of ZnO NPs to radish, rape, and ryegrass was not directly from their dissolution in bulk aqueous solutions (Lin and Xing 2007, 2008). However, Franklin et al. believed that toxicity experiments using the freshwater alga Pseudokirchneriella subcapitata revealed comparable toxicity for $\mathrm{ZnO} N P s$ and $\mathrm{ZnCl}_{2}$, attributable solely to dissolved Zn (Franklin et al. 2007). Therefore, toxicity of $\mathrm{ZnO}$ NPs, caused by particle-dependent effects or by dissolution, should be further evaluated and probably should be examined case by case (Jiang et al. 2009).

Plants are a critical component of ecosystems and serve both as important ecological receptors and as a potential pathway for the transport and bioaccumulation of nanoparticles into food chains (Zhu et al. 2008) and are considered to be one of the groups of organisms that will be directly impacted by nanoparticles. However, only a limited number of studies on the effects of nanoparticles on higher plants are available, with varied conclusions (negative, positive, and even protective effects) reported (Feizi et al. 2013; Lin and Xing 2008; Ma et al. 2013; Stampoulis et al. 2009; Wang et al. 1999, 2012), although a relatively broad range of species have been tested. $\mathrm{ZnO}$ NPs were reported to inhibit root elongation of radish, rape, ryegrass, lettuce, corn, and cucumber, and toxicity was considered mainly due to a particle-dependent effect, although soluble $\mathrm{Zn}$ from particles could not be ruled out (Lin and Xing 2007). Manzo et al. also found that ZnO NPs affected root elongation of garden cress and caused genotoxicity to broad bean (Manzo et al. 2011). In contrast, Stampoulis et al. demonstrated that $\mathrm{ZnO}$ NPs at $1,000 \mathrm{mg} \mathrm{L}^{-1}$ in hydroponic solution did not show any effects on seed germination, root elongation, or biomass of zucchini (Stampoulis et al. 2009). The controversy in the literature indicates that the phytotoxicity of nanoparticles is still poorly understood. Moreover, even though nanoparticles do not show acute toxic effects on plants, they may accumulate in vivo (Lin and Xing 2008; Lin et al. 2009; Stampoulis et al. 2009), be transported into the food chain (Judy et al. 2011), and transferred to the next generation potentially (Lin et al. 2009).
Many studies have found that although having obviously negative effect on root elongation, nanoparticles did not affect seed germination (Lin and Xing 2007; Wang et al. 2012). Researchers attributed such a phenomenon to the selective permeability of seed coats. Also, seed coats may protect seed from toxicity by other pollutants. Lane and Martin demonstrated that seed coats of Raphanus sativus were a strong barrier to lead and prevented contamination of embryos until the seed coats were torn apart by the germinating embryonic roots (Lane and Martin 1977). Wierzbicka and Obidzińska also found that 72 and $61 \%$ of the plant species studied had impermeable seed coats to lead and barium ions respectively (Wierzbicka and Obidzinska 1998). Therefore, we hypothesized that seed coats might protect from engineered nanoparticles entering seeds, and thereby, mitigation of the phytotoxicity of ENPs. The objectives of this study were to understand the toxic effects of ZnO NPs on seed germination and root elongation of corn and cucumber and mechanisms of phytotoxicity of the nanopaticles in relation to seed coats isolation and plant uptake of the nanoparticles.

\section{Materials and methods}

\section{Nanoparticles}

ZnO NPs were purchased from Shanghai Aladdin Reagent Co., Ltd, with a purity of $99.5 \%$ and particle size of $30 \pm$ $10 \mathrm{~nm}$ provided by the producer. The size of ZnO NPs measured in our laboratory using a Hitachi S-4800 Field Emission Scanning Electron Microscope (Hitachi S-4800 FE-SEM) was $30 \pm 12 \mathrm{~nm}$ (Supplementary Material Fig. S1). X-ray difffaction analysis (XRD, Rigaku Ultima IV) of the nanoparticles revealed a pure $\mathrm{ZnO}$ minerals composed of zincite (Supplementary Material Fig. S2). The specific surface area determined using the multi-point Brunauer-Emmett-Teller (BET) method was $42.0 \mathrm{~m}^{2} \mathrm{~g}^{-1}$. All other chemicals of analytical reagent grade were purchased from Sinopharm Chemical Regent Co., Ltd, China.

\section{Preparation of particle suspensions}

The nanoparticles were suspended directly in deionized water (DI-water) and dispersed by ultrasonic vibration $(500 \mathrm{~W}$, $40 \mathrm{kHz}$ ) for $30 \mathrm{~min}$. During ultrasonication, the suspensions were continuously stirred to avoid aggregation of the particles. Then the size of the nanoparticle aggregates was measured by dynamic light scattering (DLS, Malvern Zetasizer Nano ZS90). After 5 days, the $\mathrm{ZnO}$ suspensions were centrifuged $(10,000 \times g$ for $30 \mathrm{~min})$ and were filtered through $0.22 \mu \mathrm{m}$ glass filters. The $\mathrm{Zn}$ concentration in the filtrate was determined using an inductively coupled plasma mass 
spectrometry (ICP-MS, PerkinElmer ELAN DRC II). $\mathrm{Zn}^{2+}$ solution was prepared by dissolving $\mathrm{Zn}\left(\mathrm{NO}_{3}\right)_{2}$ in DI-water.

\section{Seeds}

Corn (Zea mays L.) and cucumber (Cucumis sativus L.) seeds, which are among the 10 species recommended by the US Environmental Protection Agency (USEPA) for the determination of ecological effects of pesticides and toxic substances and are also commonly used in phytotoxicity testing (Lin and Xing 2007; Migliore et al. 2003; Service 2003), were purchased from Yantai Dazhong Seed Co., Ltd. The average germination rates of all plant seeds were $>85 \%$ as shown in a trial study. Seeds were kept dry in darkness at room temperature before use.

\section{Germination experiments}

Corn and cucumber seeds were immersed in a $10 \% \mathrm{NaClO}$ solution for $10 \mathrm{~min}$ and rinsed three times with DI-water to ensure surface sterility. The seeds were then soaked in DIwater, nanoparticle suspensions $(10,100$, and $1,000 \mathrm{mg} \mathrm{ZnO}$ NPs L ${ }^{-1}$ ), or $\mathrm{Zn}^{2+}$ solution (10 and $100 \mathrm{mg} \mathrm{Zn} \mathrm{L}^{-1}$ ), respectively, for $2 \mathrm{~h}$. One piece of filter paper was put into each $100 \times$ $15 \mathrm{~mm}$ Petri dish, and $5 \mathrm{~mL}$ of a test medium containing $\mathrm{ZnO}$ NPs and $\mathrm{Zn}^{2+}$ as mentioned above was added. Seeds were subsequently placed onto the filter paper, with 10 seeds per dish and $1 \mathrm{~cm}$ or larger distance between each seed. Petri dishes were covered and placed in an incubator. There were four replicate dishes for each treatment. Germination was quantified when the bud length surpassed half of the seed length (Wang et al. 2012). After 5 days in the dark under room temperature, more than $85 \%$ of the control seeds had germinated. Then, the germination was halted, seed germination rate was calculated, and seedling root length was measured.

To investigate whether there was protective effect of seed coats on the phytotoxicity of nanopaticles during germination, after surface sterilization, the seed coats of corn were removed carefully. The corn seeds without seed coats were then treated the same as those with seed coats as mentioned above.

After germination, the seedlings in each Petri dish were collected as a whole, soaked in $20 \mathrm{mmol} \mathrm{L}^{-1} \mathrm{Na}_{2}$ EDTA solution for $2 \mathrm{~h}$, and then washed with tap water followed by three rinses with DI-water to remove metal ions and nanoparticles adhered to surface (Wang et al. 2012). Zn contents in seeds from all treatments were measured by ICP-MS after $\mathrm{HNO}_{3}$ digestion. There were four replicates for each treatment.

Fresh roots were thoroughly washed with DI-water. Root samples were prefixed in $5 \%$ glutaraldehyde, washed in $0.1 \mathrm{~mol} \mathrm{~L}^{-1} \mathrm{pH} 7.2$ phosphate buffer, postfixed in $1 \%$ osmium tetroxide, dehydrated in a graded series of ethanol, and embedded in epoxy resin. Samples were sectioned to 60 $80 \mathrm{~nm}$ thick using an Ultracut E Microtome (RMC Power
Tome XL) and stained with uranyl acetate. The root tissues were then placed on $\mathrm{Cu}$-based grids and observed with a transmission electron microscope (TEM, JEM 1400-plus).

\section{Statistical analysis}

Each treatment was conducted with at least three replicates, and the results were presented as mean $\pm \mathrm{SD}$ (standard deviation). The statistical analysis of experimental data was performed by means of one-way analysis of variance with the Fisher LSD post hoc test using IBM SPSS Statistics 19.0. Statistical significance was accepted when the probability of the result assuming the null hypothesis $(p)$ is less than 0.05 .

\section{Results}

\section{Germination and root elongation of corn and cucumber}

Effects of $\mathrm{ZnO}$ NPs and $\mathrm{Zn}^{2+}$ on the germination of corn and cucumber seeds are shown in Fig. 1. In general, no statistically significant reduction in germination was observed in the various treatments of corn and cucumber except for $100 \mathrm{mg} \mathrm{L}^{-1}$ $\mathrm{Zn}^{2+}$ which inhibited cucumber germination completely.

Figure 2 presents root elongation of corn and cucumber in the presence of nanoparticles and $\mathrm{Zn}^{2+}$. It is clear from Fig. $2 \mathrm{~A}$ that root elongation of corn in 10 and $100 \mathrm{mg} \mathrm{L}^{-1} \mathrm{ZnO} \mathrm{NPs}$ batches was not significantly reduced $(p<0.05)$ relative to that of the control which reached $51.6 \mathrm{~mm}$, while $10 \mathrm{mg} \mathrm{L}^{-1} \mathrm{ZnO}$ NPs significantly promoted the root length of corn. However, when the concentration reached $1,000 \mathrm{mg} \mathrm{L}^{-1}$, ZnO NPs significantly inhibited root length by $17.3 \%(p<0.05)$, while $10 \mathrm{mg} \mathrm{L}^{-1} \mathrm{Zn}^{2+}$ significantly promoted root growth compared with the control $(p<0.01)$, and $100 \mathrm{mg} \mathrm{L}^{-1} \mathrm{Zn}^{2+}$ displayed no effect on root length $(p<0.05)$. In cucumber batches, reductions against the control were observed in all treatments of $\mathrm{ZnO}$, and dose-response was present in nanoparticles (Fig. 2b). Root growth was clearly reduced with increasing concentrations, and $\mathrm{Zn}^{2+}$ was more toxic to cucumber than $\mathrm{ZnO}$ NPs which inhibited root elongation completely at a concentration of $100 \mathrm{mg} \mathrm{L}^{-1}$. The root elongation of cucumber was observed to be significantly negatively correlated with the dissolved $\mathrm{Zn}$ concentration in solution $(R=-0.813$, $p<0.05$ ).

\section{Germination and root elongation of corn without seed coats}

To examine whether seed coats could mitigate the phytotoxicity of nanoparticles, germination and root elongation of corn without seed coats in the presence of $\mathrm{ZnO}$ or $\mathrm{Zn}^{2+}$ were evaluated. All treatments had no negative impact on germination of corn without seed coats (Fig. 3), and germination rate was 

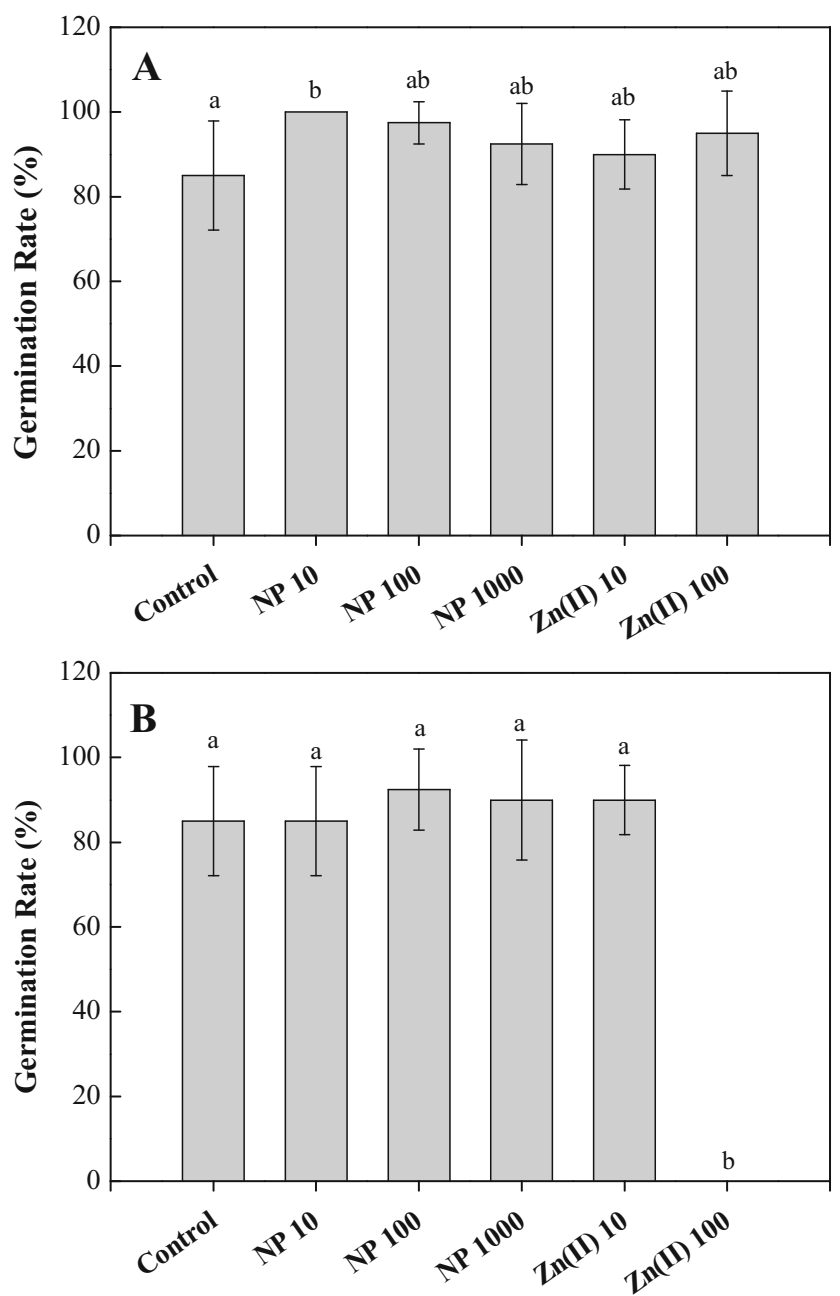

Fig. 1 Effect of nanoparticles on germination of corn (a) and cucumber (b) in the presence of DI-water (Control), $10 \mathrm{mg} \mathrm{L}^{-1} \mathrm{ZnO}$ NPs (NP10), $100 \mathrm{mg} \mathrm{L}^{-1} \mathrm{ZnO}$ NPs (NP100), 1,000 $\mathrm{mg} \mathrm{L}^{-1} \mathrm{ZnO}$ NPs (NP1000), $10 \mathrm{mg} \mathrm{L}^{-1} \mathrm{Zn}^{2+}$ (Zn(II) 10), and $100 \mathrm{mg} \mathrm{L}^{-1} \mathrm{Zn}^{2+}$ (Zn(II) 100). Different letters represent significant difference between the treatment means $(p<0.05)$

not significantly different from that of the corresponding treatments of corn with intact seed coats (Fig. 1). Without seed coats, root length of corn in DI-water reached $67 \mathrm{~mm}$ after 5 days, while it was $52 \mathrm{~mm}$ with seed coats (Fig. 3). This suggests that seed coats delayed root elongation. In addition, $1,000 \mathrm{mg} \mathrm{L}^{-1} \mathrm{ZnO}$ NPs inhibited root elongation by $26 \%$, significantly greater than the $17 \%$ in the corresponding batch of corn with intact seed coats $(p<0.05)$. $\mathrm{Zn}^{2+}$ treatments did not cause any inhibition in root elongation, verifying their non-toxicity to root growth of corn in the concentrations tested.

\section{Zn uptake during germination}

Corn is monocotyledonous and its nutrients are supplied by the endosperm during germination. The endosperm will shrink instead of developing into a part of seedlings after
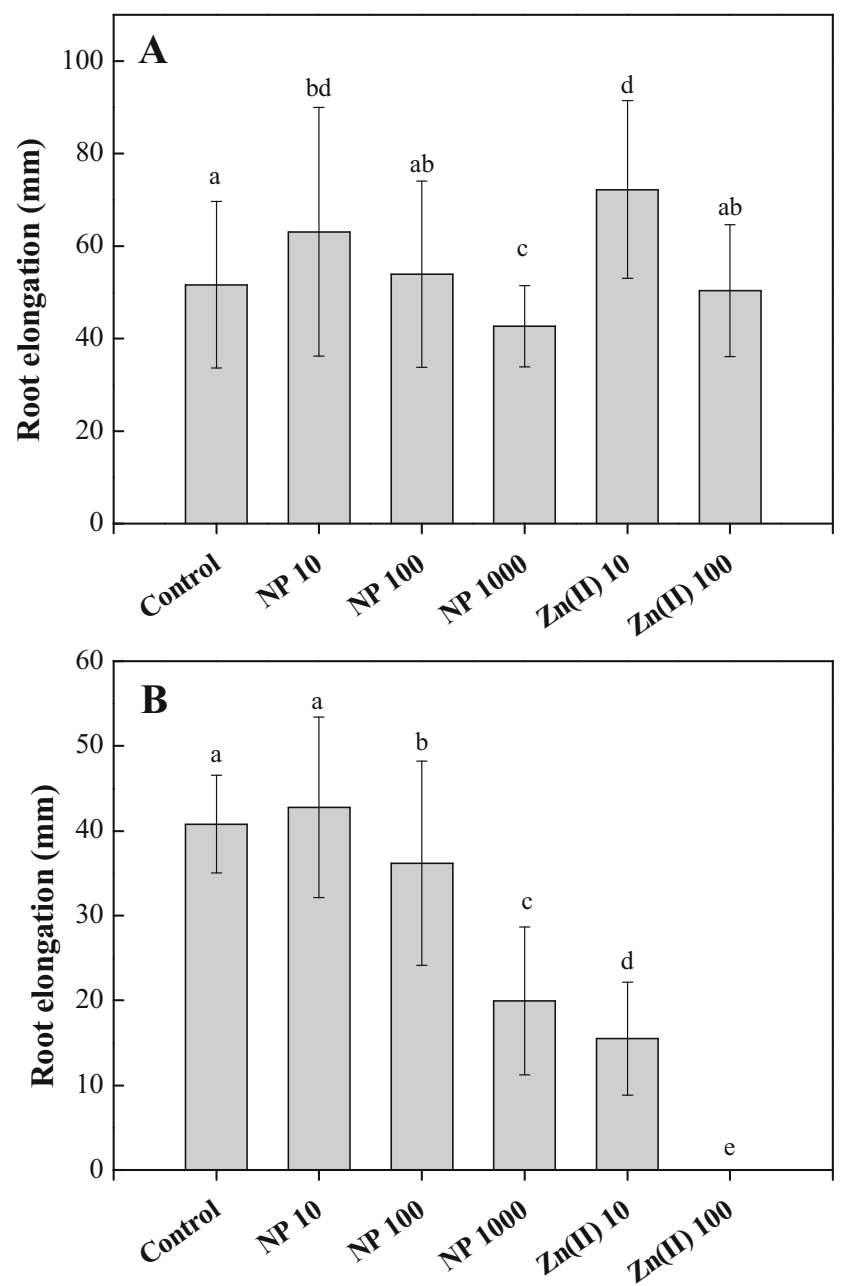

Fig. 2 Effect of nanoparticles on root elongation of corn (a) and cucumber (b) in the presence of $\mathrm{ZnO}$ NPs or $\mathrm{Zn}(\mathrm{II})$. Different letters represent significant difference between the treatment means $(p<0.05)$

nutrients are depleted. In contrast, cucumber is dicotyledonous and its cotyledons are vegetative organs which develop

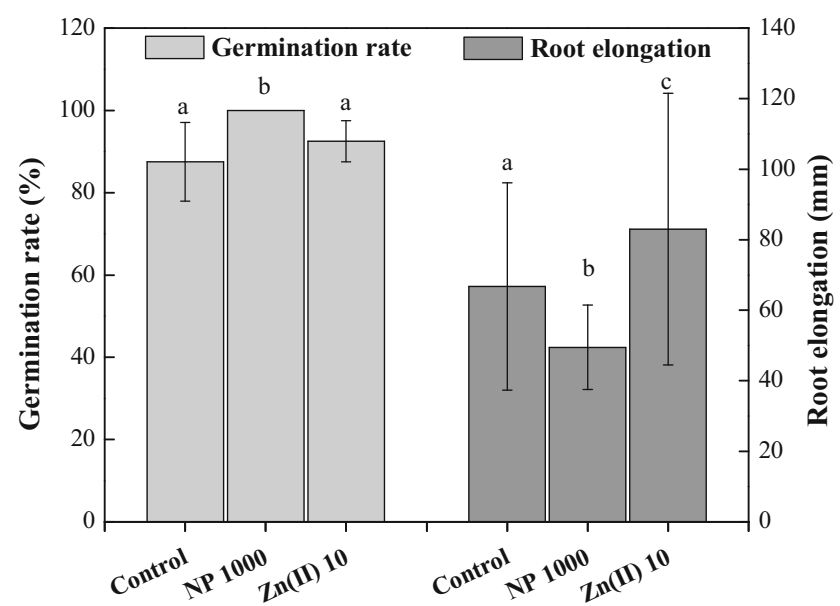

Fig. 3 Effect of nanoparticles on germination rate and root elongation of corn without seed coat. Different letters represent significant difference between the treatment means $(p<0.05)$ 
into the first leaf providing nutrient by photosynthesis. Given this, the root and endosperm of corn were digested and tested for $\mathrm{Zn}$, while cucumber seed was analyzed entirely.

All treatments showed higher $\mathrm{Zn}$ concentrations compared with the control (Fig. 4). Dose-dependent responses were present in all treatments of ZnO NPs. For corn, whether seed coats were intact or not, Zn uptake by the root was several
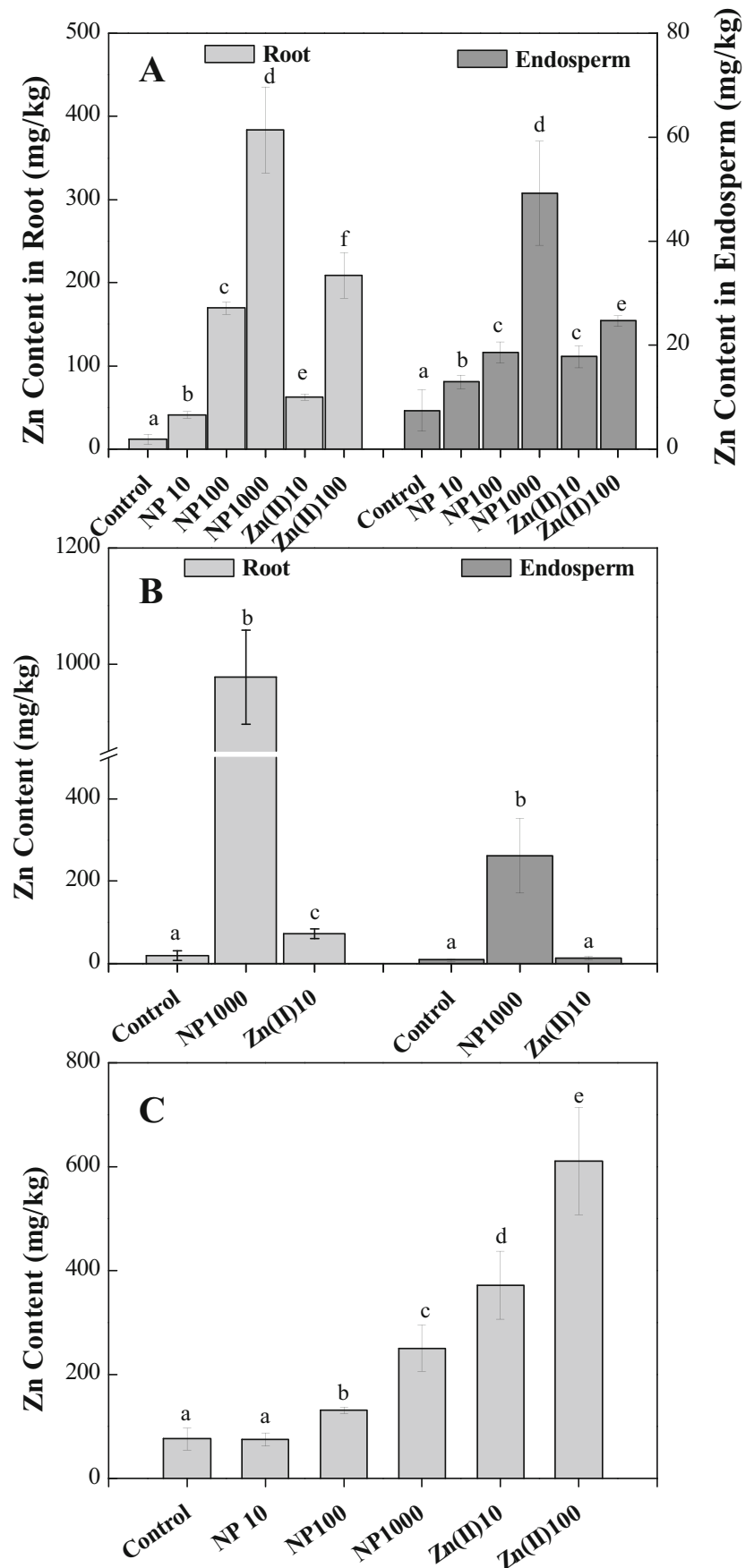

Fig. $4 \mathrm{Zn}$ contents taken up during the germination under different treatments in root (left $Y$ axis) and endosperm (right $Y$ axis) of corn with seed coat (a), without seed coat (b), and in seed of cucumber (c). Different letters represent significant difference between the treatment means $(p<0.05)$ times higher than that by the endosperm. In addition, $\mathrm{Zn}$ accumulation by root and endosperm of corn without seed coats was much higher than that of corn with seed coats. Taking 1, $000 \mathrm{mg} \mathrm{L}^{-1} \mathrm{ZnO}$ NPs for example, $\mathrm{Zn}$ in root of corn with seed coats was $384 \mathrm{mg} \mathrm{kg}^{-1}$, while it was $978 \mathrm{mg} \mathrm{kg}^{-1}$ without seed coats, and the absence of seed coats resulted in about six times more $\mathrm{Zn}$ content in endosperm. Compared with $\mathrm{Zn}^{2+}$, $\mathrm{ZnO}$ NPs resulted in higher uptake of $\mathrm{Zn}$ by corn, in both root and endosperm.

In batches of cucumber, $\mathrm{Zn}$ content was also higher out of all treatments relative to control. Similar to the response of root elongation to soluble $\mathrm{Zn}$, the $\mathrm{Zn}$ contents in cucumber seed were significantly correlated with soluble $\mathrm{Zn}$ in solution $(R=0.888, p<0.05)$.

\section{Discussion}

\section{Phytotoxicity of the ZnO NPs}

Seed germination and root elongation comprise a rapid and widely used acute phytotoxicity test method possessing several advantages: sensitivity, simplicity, low cost, and suitability for unstable chemicals or samples (Munzuroglu and Geckil 2002; Wang et al. 2001).

Like the germination experiments previously reported in which negligible adverse impact of nanoparticles on the germination of tested plants was observed (Lin and Xing 2007; Stampoulis et al. 2009; Wang et al. 2012), the germination of corn and cucumber in this study was not impacted by $\mathrm{ZnO}$ NPs. We hypothesize that seed germination was insensitive to nanoparticles because of selective permeability of the seed coats, insufficient pollutant concentrations, short exposure times, or other uncharacterized biological processes. It is, however, unclear which factor played a more important role and this needs further investigation.

$\mathrm{ZnO}$ NPs at $1,000 \mathrm{mg} \mathrm{L}^{-1}$ in this study significantly inhibited root elongation of corn and cucumber. It should also be noted that higher $\mathrm{Zn}$ contents were found in the roots than in the endosperm of corn, indicating that imbibition of $\mathrm{Zn}$ occurred mainly after the radicles penetrated the seed coats. Previous work suggests that after penetrating the seed coats the emerging radicals rapidly absorb nutrients and water and contact the nanoparticles directly, thus, maximizing particle exposure (Wang et al. 2012). In this scenario, a more significant phytotoxic effect was observed on root elongation than on seed germination. In addition, cucumber seemed more susceptible to ZnO NPs than corn in this study. This is to be expected due to the different sensitivities of different species. Besides, smaller seeds have higher surface-area-to-volume ratios than larger ones, which increases their exposure (per unit volume) to the test solution (Lee et al. 2010). 


\section{Mechanism of phytotoxicity by ZnO NPs}

The current study suggests two distinctive mechanisms of $\mathrm{ZnO}$ NPs toxicity on corn and cucumber, respectively. The first is related to the dissolution of $\mathrm{ZnO} N P$ s to $\mathrm{Zn}^{2+}$. $\mathrm{ZnO}$ NPs can dissolve under many environmental conditions (Bian et al. 2011) including the neutral conditions in this study (Table 1). The dissolution of particles combined with high toxicity of dissolved $\mathrm{Zn}$ often explains why $\mathrm{ZnO}$ NPs have been found to be the most toxic compared with other metal oxides nanoparticles (Ma et al. 2013). Based on the findings that root elongation of cucumber was significantly negatively correlated with dissolved $\mathrm{Zn}$ in solution $(R=-0.813, p<0.05)$, it can be inferred that toxicity of ZnO NPs to cucumber was largely due to the dissolved $\mathrm{Zn}$, although it is not yet well understood to what extent the dissolved $\mathrm{Zn}$ contributes to $\mathrm{ZnO}$ NPs toxicity. In accordance with the response of root elongation to soluble $\mathrm{Zn}$, the significant correlation of $\mathrm{Zn}$ content in seedlings to soluble $\mathrm{Zn}$ in solution $(R=0.888$, $p<0.05$ ) indicates that $\mathrm{Zn}$ entered the cucumber seed mainly in the form of soluble Zn. Furthermore, no ZnO NPs was found in TEM image of cucumber root under the treatment of $1,000 \mathrm{mg} \mathrm{L}^{-1} \mathrm{ZnO}$ NPs. $\mathrm{Zn}$ is an essential element for plants, but it is toxic at high effective concentrations (EC50substrate $\mathrm{Zn}$ concentration resulting in $50 \%$ biomass reduction) ranging from 43 to $996 \mathrm{mg} \mathrm{L}^{-1} \mathrm{Zn}$ within different plant species (Paschke et al. 2006). $\mathrm{Zn}^{2+}$ reduces the germination of a range of plant seeds and also inhibits growth of their roots, stems, and leaves (El-Ghamery et al. 2003; Munzuroglu and Geckil 2002).

Besides particle dissolution, nanoparticulate size effect represents another important mechanism of toxicity for $\mathrm{ZnO}$ NPs. Results of corn batches shows that $1,000 \mathrm{mg} \mathrm{L}^{-1} \mathrm{ZnO} \mathrm{NPs}$ significantly inhibited root elongation of corn relative to the control and $\mathrm{Zn}^{2+}$. It should be noted that dissolved $\mathrm{Zn}$ in all $\mathrm{ZnO}$ NPs suspensions in this experiment were below $10 \mathrm{mg} \mathrm{L}^{-1}$ (Table 1), indicating that the toxicity of $\mathrm{ZnO}$ NPs to corn was not attributable to the $\mathrm{Zn}^{2+}$ dissolved from nanoparticles. Compared with $\mathrm{Zn}^{2+}$, $\mathrm{ZnO}$ NPs were more accessible to the root and endosperm of corn (Fig. 4a, b), suggesting that nanoparticles might be the main chemical state penetrating into roots and endosperm exposed to $\mathrm{ZnO}$ NPs. Moreover,

Table 1 Size distributions and $\mathrm{Zn}$ dissolution of nanoparticles

\begin{tabular}{llll}
\hline & $\begin{array}{l}\text { Size distribution }^{\mathrm{a}} \\
(\mathrm{nm})\end{array}$ & $\begin{array}{l}\text { Average size } \\
(\mathrm{nm})\end{array}$ & $\begin{array}{l}\text { Soluble Zn } \\
\left(\mathrm{mg} \mathrm{L}^{-1}\right)\end{array}$ \\
\hline ZnO NPs 10 & $91-122$ & $106 \pm 13$ & $0.79 \pm 0.13$ \\
ZnO NPs 100 & $220-342$ & $279 \pm 35$ & $1.47 \pm 0.05$ \\
ZnO NPs 1,000 & $531-6439$ & $1,102 \pm 403$ & $7.67 \pm 0.71$ \\
\hline
\end{tabular}

${ }^{\mathrm{a}}$ These data are in hydrodynamic size measured by DLS
TEM images showed the presence of dark clusters with irregular shape and margin (particle aggregates) in the corn roots under $1,000 \mathrm{mg} \mathrm{L}^{-1}$ treatment (Fig. 5b). The size of the particles in these aggregate was measured to be identified to the size of $\mathrm{ZnO}$ NPs in higher magnification TEM images

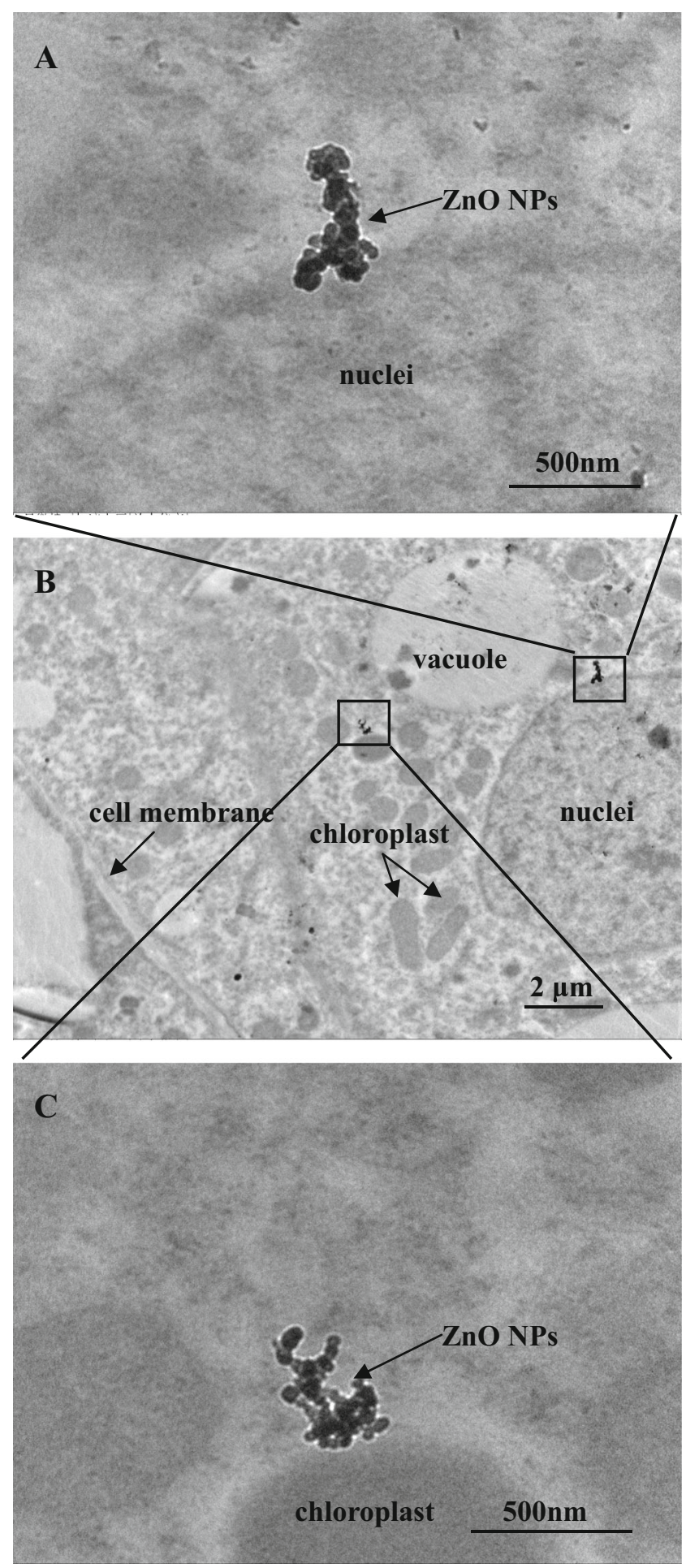

Fig. 5 TEM images showing the presence of ZnO NPs in the cells of corn root under the treatment of $1,000 \mathrm{mg} \mathrm{L}^{-1} \mathrm{ZnO}$ NPs. a and $\mathbf{c}$ are magnified images of the squared regions in $\mathbf{b}$ 
(Fig. 5a, c). Such dark clusters were not observed in either control or $\mathrm{Zn}^{2+}$ treatments (Supplementary Material Fig. S3). Based on these observations, it was reasonably concluded that $\mathrm{ZnO}$ NPs could enter into the roots of corn. Taken together, it could be hypothesized that potential phytotoxicity of $\mathrm{ZnO}$ NPs to corn was mainly due to the nanoparticles per se rather than the $\mathrm{Zn}^{2+}$ dissolved.

From a retrospection of previous studies reported in which root elongation of different species was reduced by the nanoparticles themselves (Lin and Xing 2007; Wang et al. 2012) or not impacted at all (Stampoulis et al. 2009), a conclusion could be reached that the mechanisms of phytotoxicity of nanoparticles are very complicated and difficult to elucidate. Different plant species, a wide range of nanoparticle concentrations, and even tiny differences in experimental conditions may bring about different or even completely opposite experimental results.

Interestingly, hydrodynamic size of aggregation in 1, $000 \mathrm{mg} \mathrm{L}^{-1}$ ZnO NPs measured by DLS reached 1,102 nm which exceeds the scope of nanosize and conversely was close to the size of bulk particles. However, the nanotoxicity of $\mathrm{ZnO}$ NPs was still displayed completely. Given that, we hypothesize that it is the individual sizes rather than aggregate sizes that appear to determine the toxicity of $\mathrm{ZnO}$ NPs. In addition to $\mathrm{ZnO} N P s$ in this study, the toxicity of $\mathrm{Al}_{2} \mathrm{O}_{3} \mathrm{NPs}$ and $\mathrm{SiO}_{2}$ NPs were also assumed to be independent of aggregate size (Jiang et al. 2009).

Seed germination is the start of plant growth and always plays an important role in the life cycle of plants. It is reported that nanoparticle pollutants, such as fullerene $\mathrm{C}_{70}$, commercial quantum dots, and nano-Au exposed to seed, were always transferred during the whole lifetime of plant growth through various pathways and were eventually present in progeny or biomagnified in primary consumers of plants (Judy et al. 2011; Lin et al. 2009; Zhu et al. 2010). We could reasonably draw a conclusion that although the nanoparticle uptake by seedlings might have no negative effect on seed germination or root elongation, they could accumulate and translocate into plants and thus affect subsequent metabolic activity of plants. The accumulation and translocation in plants of $\mathrm{Zn}$ from nanoparticles may indicate some potential for environmental impacts via trophic transfer and cycling.

\section{Role of seed coats of corn in the presence of nanoparticles}

The seed coats protect the seed (embryo and endosperm) from mechanical damage (insects, abrasion, and crushing), infection (bacteria, virus particles, and fungi), desiccation, freezing, and in some cases, the effects of fire. Seed coats also provide a time-delay factor to the germination of the seed which needs to be wet or immersed in water to initiate germination. Efficient seed germination and early seedling establishment are important processes in commercial agriculture.
Sometimes people damage seed coats by means of carving by rasp, soaking in acid, base or other reagents, and ultrasonication to accelerate germination.

Seed coats with selective permeability and secrete seed mucilage are considered to play a very important role in protecting the embryo from harmful external factors (Kurepa et al. 2010; Lin and Xing 2007). Pollutants may not affect germination if they cannot pass through seed coats. This is the explanation that seed germination was not greatly affected by nanoparticles in many previous studies (Kurepa et al. 2010; Lin and Xing 2007; Wang et al. 2012). Therefore, it is necessary to investigate whether and to what extent seed coats can alleviate the phytotoxic effects of nanoparticles on germination and root elongation.

Our observation that all $\mathrm{ZnO}$ NPs treatments did not have negative effect on germination of corn, regardless of seed coats removal (Fig. 3a), suggests that seed coats might not be the principal factor that mitigated toxicity to germination of corn. It might be insufficient concentrations, low toxicity of the nanoparticles investigated, or other uncharacterized biological processes that lead to the non-significant impact of nanoparticles on germination of corn. However, in 1, $000 \mathrm{mg} \mathrm{L}^{-1} \mathrm{ZnO}$ NPs, a higher inhibition rate of root growth without seed coats was found than with intact seed coats (Fig. 3). This implies that seed coats can alleviate toxicity of $\mathrm{ZnO}$ NPs on root elongation of corn. This result is in accordance with the fact that seed coats can prevent a great proportion of $\mathrm{ZnO}$ NPs from entering into the root and endosperm of seed (Fig. 4). Lane and Martin demonstrated that seed coats of $R$. sativus were a strong barrier to $\mathrm{Pb}$ and prevented contamination of embryos until the seed coats were torn apart by the germinating embryonic root (Lane and Martin 1977). However, considerable toxicity to root elongation and $\mathrm{Zn}$ content in corn with seed coats manifested that plant could not be sufficiently protected by their seed coats. Carbon nanotubes (CNTs) were confirmed to be able to penetrate thick seed coats into tomato seeds by Raman spectroscopy and to penetrate root systems by TEM (Khodakovskaya et al. 2009). Previous studies indicate that engineered nanoparticles can penetrate an intact seed coat via the intercellular spaces $(<10 \mu \mathrm{m})$ in the parenchyma which are filled with aqueous media facilitating the transport of soluble nutrients as well as small particles to the embryo (Lee et al. 2010; Van Dongen et al. 2003).

\section{Conclusions}

To characterize the potential risks of nanoparticles, it is necessary to improve our knowledge of their bioavailability and toxicity. The interactions between nanoparticles and plants are of particular concern as plants closely interact with the atmosphere, water, and soil, and constitute one of the main routes 
of exposure for consumers. We tested the phytotoxicity of $\mathrm{ZnO}$ NPs to corn and cucumber during germination. The germination of both species was unaffected by the nanoparticles, but $\mathrm{ZnO}$ NPs exhibited toxicity to root elongation. Nanoparticulate size and soluble $\mathrm{Zn}$ from ZnO NPs were reckoned to contribute to the inhibition on root elongation of corn and cucumber, respectively. Seed coats of corn may have mitigated the toxicity of $\mathrm{ZnO}$ NPs on root elongation and prevented a large proportion of $\mathrm{ZnO}$ NPs from entering the root and endosperm, but might not be the principal factor that prevented toxicity on germination. Although showing no or less adverse effects during germination, abundant $\mathrm{Zn}$ uptake in corn and cucumber was detected and might affect the growth of the plants subsequently or accumulate in higher trophic levels.

Acknowledgments This work was supported by the National Natural Science Foundation of China (41171248 and 41230858).

\section{Compliance with ethical standards}

Conflict of interest The authors declare that they have no conflict of interest.

\section{References}

Adams LK, Lyon DY, Alvarez PJJ (2006) Comparative eco-toxicity of nanoscale $\mathrm{TiO}_{2}, \mathrm{SiO}_{2}$, and $\mathrm{ZnO}$ water suspensions. Water Res 40: 3527-3532

Bian SW, Mudunkotuwa IA, Rupasinghe T, Grassian VH (2011) Aggregation and dissolution of $4 \mathrm{~nm} \mathrm{ZnO}$ nanoparticles in aqueous environments: influence of $\mathrm{pH}$, ionic strength, size, and adsorption of humic acid. Langmuir 27:6059-6068

Boxall A, Chaudhry Q, Sinclair C, Jones A, Aitken R, Jefferson B, Watts C (2007) Current and future predicted environmental exposure to engineered nanoparticles. Central Science Laboratory, Department of the Environment and Rural Affairs, London, p 89

Brayner R, Ferrari-Iliou R, Brivois N, Djediat S, Benedetti MF, Fievet F (2006) Toxicological impact studies based on Escherichia coli bacteria in ultrafine $\mathrm{ZnO}$ nanoparticles colloidal medium. Nano Lett 6: 866-870

Colvin VL (2003) The potential environmental impact of engineered nanomaterials. Nat Biotechnol 21:1166-1170

El-Ghamery AA, El-Kholy MA, Abou El-Yousser MA (2003) Evaluation of cytological effects of $\mathrm{Zn}^{2+}$ in relation to germination and root growth of Nigella sativa L. and Triticum aestivum L. Mutat Res Genet Toxicol Environ Mutagen 537:29-41

Feizi H, Kamali M, Jafari L, Moghaddam PR (2013) Phytotoxicity and stimulatory impacts of nanosized and bulk titanium dioxide on fennel (Foeniculum vulgare Mill). Chemosphere 91:506-511

Franklin NM, Rogers NJ, Apte SC, Batley GE, Gadd GE, Casey PS (2007) Comparative toxicity of nanoparticulate $\mathrm{ZnO}$, bulk $\mathrm{ZnO}$, and $\mathrm{ZnCl}_{2}$ to a freshwater microalga (Pseudokirchneriella subcapitata): the importance of particle solubility. Environ Sci Technol 41:8484-8490

Ge YG, Schimel JP, Holden PA (2011) Evidence for negative effects of $\mathrm{TiO}_{2}$ and $\mathrm{ZnO}$ nanoparticles on soil bacterial communities. Environ Sci Technol 45:1659-1664
Gottschalk F, Sonderer T, Scholz RW, Nowack B (2009) Modeled environmental concentrations of engineered nanomaterials $\left(\mathrm{TiO}_{2}, \mathrm{ZnO}\right.$, $\mathrm{Ag}, \mathrm{CNT}$, Fullerenes) for different regions. Environ Sci Technol 43: 9216-9222

Heinlaan M, Ivask A, Blinova I, Dubourguier HC, Kahru A (2008) Toxicity of nanosized and bulk $\mathrm{ZnO}, \mathrm{CuO}$ and $\mathrm{TiO}_{2}$ to bacteria Vibrio fischeri and crustaceans Daphnia magna and Thamnocephalus platyurus. Chemosphere 71:1308-1316

$\mathrm{Hu}$ CW, Li M, Cui YB, Li DS, Chen J, Yang LY (2010) Toxicological effects of $\mathrm{TiO}_{2}$ and $\mathrm{ZnO}$ nanoparticles in soil on earthworm Eisenia fetida. Soil Biol Biochem 42:586-591

Jiang W, Mashayekhi H, Xing BS (2009) Bacterial toxicity comparison between nano- and micro-scaled oxide particles. Environ Pollut 157: 1619-1625

Judy JD, Unrine JM, Bertsch PM (2011) Evidence for biomagnification of gold nanoparticles within a terrestrial food chain. Environ Sci Technol 45:776-781

Ju-Nam Y, Lead JR (2008) Manufactured nanoparticles: an overview of their chemistry, interactions and potential environmental implications. Sci Total Environ 400:396-414

Khodakovskaya M, Dervishi E, Mahmood M, Xu Y, Li ZR, Watanabe F, Biris AS (2009) Carbon nanotubes are able to penetrate plant seed coat and dramatically affect seed germination and plant growth. ACS Nano 3:3221-3227

Kurepa J, Paunesku T, Vogt S, Arora H, Rabatic BM, Lu JJ, Wanzer MB, Woloschak GE, Smalle JA (2010) Uptake and distribution of ultrasmall anatase $\mathrm{TiO}_{2}$ Alizarin red S nanoconjugates in Arabidopsis thaliana. Nano Lett 10:2296-2302

Lane SD, Martin ES (1977) Histochemical investigation of lead uptake in Raphanus sativus. New Phytol 79:281-286

Lee CW, Mahendra S, Zodrow K, Li D, Tsai YC, Braam J, Alvarez PJJ (2010) Developmental phytotoxicity of metal oxide nanoparticles to Arabidopsis thaliana. Environ Toxicol Chem 29:669-675

Lin DH, Xing BS (2007) Phytotoxicity of nanoparticles: inhibition of seed germination and root growth. Environ Pollut 150:243-250

Lin DH, Xing BS (2008) Root uptake and phytotoxicity of $\mathrm{ZnO}$ nanoparticles. Environ Sci Technol 42:5580-5585

Lin SJ, Reppert J, Hu Q, Hudson JS, Reid ML, Ratnikova TA, Rao AM, Luo H, Ke PC (2009) Uptake, translocation, and transmission of carbon nanomaterials in rice plants. Small 5:1128-1132

Ma HB, Williams PL, Diamond SA (2013) Ecotoxicity of manufactured $\mathrm{ZnO}$ nanoparticles - a review. Environ Pollut 172:76-85

Manzo S, Rocco A, Carotenuto R, Picione FD, Miglietta ML, Rametta G, Di Francia G (2011) Investigation of ZnO nanoparticles' ecotoxicological effects towards different soil organisms. Environ Sci Pollut Res Int 18:756-763

Migliore L, Cozzolino S, Fiori M (2003) Phytotoxicity to and uptake of enrofloxacin in crop plants. Chemosphere 52:1233-1244

Munzuroglu O, Geckil H (2002) Effects of metals on seed germination, root elongation, and Coleoptile and hypocotyl growth in Triticum aestivum and Cucumis sativus. Arch Environ Contam Toxicol 43: 203-213

Paschke MW, Perry LG, Redente EF (2006) Zinc toxicity thresholds for reclamation forb species. Water Air Soil Pollut 170:317-330

Roco MC, Mirkin CA, Hersam MC (2011) Nanotechnology research directions for societal needs in 2020: summary of international study. J Nanoparticle Res 13:897-919

Service RF (2003) American Chemical Society Meeting: nanomaterials show signs of toxicity. Science 300:243

Stampoulis D, Sinha SK, White JC (2009) Assay-dependent phytotoxicity of nanoparticles to plants. Environ Sci Technol 43:9473-9479

Van Dongen JT, Ammerlaan AMH, Wouterlood M, Van Aelst AC, Borstlap AC (2003) Structure of the developing pea seed coat and the post-phloem transport pathway of nutrients. Ann Bot Lond 91: 729-737 
Wang IC, Tai LA, Lee DD, Kanakamma PP, Shen CKF, Luh TY, Cheng CH, Hwang KC (1999) C-60 and water-soluble fullerene derivatives as antioxidants against radical-initiated lipid peroxidation. J Med Chem 42:4614-4620

Wang XD, Sun C, Gao SX, Wang LS, Han SK (2001) Validation of germination rate and root elongation as indicator to assess phytotoxicity with Cucumis sativus. Chemosphere 44:1711-1721

Wang ZY, Xie XY, Zhao J, Liu XY, Feng WQ, White JC, Xing BS (2012) Xylem- and phloem-based transport of $\mathrm{CuO}$ nanoparticles in maize (Zea mays L.). Environ Sci Technol 46:4434-4441
Wierzbicka M, Obidzinska J (1998) The effect of lead on seed imbibition and germination in different plant species. Plant Sci 137:155-171

Zhu H, Han J, Xiao JQ, Jin Y (2008) Uptake, translocation, and accumulation of manufactured iron oxide nanoparticles by pumpkin plants. J Environ Monit 10:713-717

Zhu XS, Wang JX, Zhang XZ, Chang Y, Chen YS (2010) Trophic transfer of $\mathrm{TiO}_{2}$ nanoparticles from daphnia to zebrafish in a simplified freshwater food chain. Chemosphere 79:928-933 